\title{
Special issue dedicated to the 100th anniversary of Nankai University
}

\author{
Jun Chen ${ }^{*} \&$ Guangxin Liang \\ College of Chemistry, Nankai University, Tianjin 300071, China
}

Received April 3, 2019; accepted April 3, 2019; published online April 15, 2019 Citation: Chen J, Liang G. Special issue dedicated to the 100th anniversary of Nankai University. Sci China Chem, 2019, 62: 521-524, https://doi.org/10.1007/
s11426-019-9476-8

Nankai University was founded in 1919 by the famous patriotic educators Yan Xiu and Zhang Boling who practiced the ideology of "Saving the Nation through Education," and it is a comprehensive university that is directly governed by the Ministry of Education; it is undergoing national strategic construction for being among world's top universities. With the motto of "Dedication to Public Interests, Acquisition of All-Round Capability, and Aspiration for Daily Progress"; holding the aim of "Knowing China and Serving China"; and honoring the outstanding alumnus Zhou Enlai, Nankai University carries forward the tradition of "Patriotism, Dedication, Innovation, and Collaboration" to cultivate talents, help academia flourish, serve the country, and inherit civilization. This year marks the centennial anniversary of its founding, a time of celebration for all the happy people of Nankai and Nankai's friends around the world.

Over the past 100 years, Nankai University's Chemistry has always stood by our nation, sharing her destiny, fighting hardships together through difficult times, and embracing the glory gained after a long time of industrious and hard work. The cultivation of its scientific research and talent has continued to significantly grow over the years. Chemistry classes were offered right from the beginning in 1919, when the university was founded. In 1921, Prof. Qiu Zongyue set up the Department of Chemistry, one of the earliest chemistry departments founded in a Chinese university. In 1923, Prof. Yang Shixian joined the Nankai faculty. He worked with

*Corresponding author (email: chenabc@nankai.edu.cn)
Prof. Qiu Zongyue to dramatically boost the development of the Department of Chemistry. In 1932, Prof. Zhang Kezhong established the Department of Chemical Engineering and the Institute of Applied Chemistry. He cooperated closely with the Yongli Alkali Manufacturing Plant in Tianjin, Huanghai's Chemistry and Chemical Research Institute, and the Lizhong Sulfuric Acid Plant, just to name a few, and they made significant contributions toward the development of the early chemical industry in Tianjin and even that of the whole country. In 1937, Nankai University was bombed by Japanese invaders and forced to move to the southwest. The next year, Nankai University united in Kunming with Peking University and Tsinghua University to form the renowned National Southwest Associated University, which was widely known as the "North Star of Higher Learning". During the period of the Second Sino-Japanese War, Prof. Yang Shixian successively served as the head of the National Southwest Associated University's Department of Chemistry and the university's provost. In 1946, Nankai University returned to Tianjin to resume its operation.

After the founding of New China, Nankai University's Chemistry flourished. In 1952, the Department of Chemistry set up four teaching and research sections, namely, inorganic chemistry, analytical chemistry, organic chemistry, and physical chemistry (while the Department of Chemical Engineering and the Institute of Applied Chemistry were merged into Tianjin University). In 1958, a macromolecule chemistry teaching and research section was added. A great number of famous scientists, such as Prof. Qiu Zongyue, 
Prof. Yang Shixian, Prof. Zhang Kezhong, Prof. Gao Zhenheng, Prof. Zhu Jiahan, Prof. Wang Dexi, Prof. Shen Panwen, Prof. He Binglin, Prof. Chen Ruyu, Prof. Chen Rongti, Prof. Wang Jiading, Prof. Chen Tianchi, Prof. Wang Jitao, and many others, laid a solid foundation for the development of chemistry and chemical engineering at Nankai University. In 1995, the College of Chemistry was established, and after the long-term efforts of many generations of scholars, the College of Chemistry (Chemical Science \& Engineering Program) has won a global academic reputation and worldwide respect, becoming a pillar of Nankai University's main disciplines.

Nankai Chemistry has always focused on the international academic frontier. In response to the major developmental needs of the country, Nankai Chemistry has continuously opened up new fields and built up new academic institutions. In October 1962, with the personal care and instruction of Premier Zhou Enlai and Vice Premier Nie Rongzhen, the Institute of Elemento-organic Chemistry was established as the first institute, out of all the New China universities, to specialize in chemistry research. Since the Chinese economic reform in 1978, the Institute of Polymer Chemistry (1984), the State Key Laboratory of Elemento-organic Chemistry (1985), the Institute of Applied Chemistry (1987), the State Key Laboratory of Adsorption and Separation Functional Polymer Materials (1989), the Institute of New Energy Materials Chemistry (1992), the National Engineering Research Center of Pesticides (1995), the Engineering Center of High Efficiency Energy Storage under the Ministry of Education (2007), the Key Laboratory of Advanced Energy Materials Chemistry under the Ministry of Education (2009), the State Key Laboratory of Pharmaceutical Chemistry Biology (2011), the Tianjin Collaborative Innovation Center of Chemical Science and Engineering (2013), the Joint Laboratory of International Cooperation on New Energy Materials Chemistry (2016), and others have been successively established. Most of these research institutions are supported by the state, ministries, or municipalities. The College of Chemistry is not only a Nankai University pillar discipline but also serves as an infrastructure for many other important disciplines (or colleges) in the university. Four colleges, or institutes, including the College of Environmental Science and Engineering, the Institute of Molecular Biology (now affiliated to the College of Life Sciences), the College of Materials Science and Engineering, and the College of Pharmacy, were all spun off our chemistry program.

Currently, the College of Chemistry has two departments (the Department of Chemistry, and the Department of Chemical Biology), three institutes (the Institute of Elementoorganic Chemistry, the Institute of Polymer Chemistry, and the Institute of Applied Chemistry and Engineering), and two research centers (the Research Center of Analytical Science, and the National Engineering Research Center of Pesticides), which cover two first-level disciplines (Chemistry and Plant Protection) and offer Ph.D. degrees in nine secondary disciplines, including Inorganic Chemistry, Analytical Chemistry, Organic Chemistry, Physical Chemistry, Polymer Chemistry and Physics, Chemical Biology, Fine Chemicals, and Pesticides and Plant Pathology. It also offers a master's degree in Materials and Chemical Engineering. The majors of undergraduate mainly include chemistry, molecular science and engineering, chemical biology, applied chemistry, renewable energy science and engineering (new engineering discipline). The education system is comprehensive, being built on a solid academic foundation. The College of Chemistry emphasizes interdisciplinary training and cherishes both basic and applied research. Many subdisciplines have been ranked in the top tiers of national universities. Among them, Chemistry has been selected as a national key first-class discipline and is undergoing plans for the national "double-first-class" construction, and pesticide science has been selected as the national key second-class discipline. In 2001 and 2007, Nankai University's Organic Chemistry and Pesticide Science were both ranked at number one in the National Key Discipline Evaluation. In 2007, 2012, and 2017, Nankai Chemistry was ranked in first position, second position, and Class A, respectively, in the National FirstLevel Discipline Evaluation.

Many great masters have worked in the Nankai Chemistry Program. In 1955, Prof. Yang Shixian was appointed as a member of the Chinese Academy of Sciences (academician); in 1957, he was appointed President of the Nankai University by the State Council; and later, he was elected Chairman of the Chinese Chemical Society. In 1980, Prof. Gao Zhenheng, Prof. He Binglin, Prof. Chen Ruyu, Prof. Chen Rongtian, and Prof. Shen Panwen were elected as members of the Chinese Academy of Sciences. Currently, there are 110 professors (including 27 specially appointed investigators) and 70 associate professors in the faculty. This includes seven academicians of the Chinese Academy of Sciences or the Chinese Academy of Engineering (including two double appointments), seven Leading Talents in Science and Technology Innovation (Entrepreneurship) in the National "Ten Thousand People Plan" Program, one Distinguished Teaching Master in the National "Ten Thousand People Plan" Program, eight specially appointed professors in the "Yangtze River Scholars Program" endowed by the Ministry of Education, 18 winners of the National Outstanding Young Scientist Grant, and 30 outstanding young scholars awarded by various national talent programs. The college also has three innovative groups funded by the National Natural Science Foundation of China, two national level teaching teams, two "111 Intellectual Introduction Bases," and three innovative groups funded by the Ministry of Education.

The College of Chemistry at Nankai University has always regarded the training of high-level professionals to meet the 
national needs as its highest priority, and the cause of education has continued to grow and make progress over the years. Since the establishment of the discipline, more than 21,000 graduates have been trained, becoming the elite and backbone of scientific and technological frontiers everywhere. In 1991, Nankai University's chemistry major was appointed as one of the first "National Basic Science Talents Training Base (Chemistry)" by the former State Education Commission. The College of Chemistry has not only trained tens of thousands of excellent undergraduate graduates but is also the earliest and most important training base for postgraduate studies in China, offering education for master's degrees, doctorates, and postdoctorates.

Our College of Chemistry professors have always actively explored the laws of growing young talent by making great efforts to improve the teaching facilities, constantly upgrading their educational concepts and teaching methods, insisting on imparting both theoretical knowledge and training of practical ability, vigorously supporting chemistry education outside the campus. In 1998, to meet the needs of teaching reform, the Chemical Experiment Teaching Center was established and became the National Experimental Teaching Demonstration Center in 2006. In 1999, the People's Daily reported Nankai Chemical Base's advanced experience in training high-quality talent in an article titled "Strengthening Theoretical Knowledge, Improving Practicing Ability". In the past ten years, five courses have been successively selected as national top-quality courses. In 2018, Prof. Zhou Qilin was chosen as one of the ten national models on teaching and education.

Since 1991, many alumni such as Liu Xinyuan, Li Zhengming, Zhuo Renxi, Yao Shouzhuo, Cheng Jinpei, Zhang Yukui, Yan Deyue, Chang Wenrui, Song Licheng, Zhang Quanxing, Zhou Qilin, Sun Jinsheng, Peng Xiaojun, and Chen Jun from the Nankai Chemistry Program have been elected as academicians of the Chinese Academy of Sciences or the Chinese Academy of Engineering. With the continuous development of education in China, the scale of the College of Chemistry's enrollment and training has been expanding. Currently, there are 1,195 undergraduates, 1,200 postgraduates (708 master's students and 492 doctoral students), and 47 postdoctoral students studying in the college.

Nankai Chemistry has always adhered to the principle of making study serve a practical purpose by emphasizing the interaction between research and production so as to serve the country. Since the founding of New China, it has been actively organizing faculties to promote innovative research to meet the major strategic needs of our nation and made dramatic contributions to the development of science and technology in our country. Pesticide science research has benefited the national economy and people's livelihoods; ion exchange resin research supported the "Two Bombs and One Star" national defense project; chemical production plants for the manufacturing of trichlorfon, malathion, and ion exchange resin have been built; and China's first nickelhydrogen batteries were made in 1980, filling a number of gaps in the energy storage field in China. Since 1978, Nankai Chemistry has won 47 first or second prizes for national education, science, and technology awards and major Tianjin scientific and technological achievements awards.

Over the last five years, the college has dedicated itself to the international academic frontier, focused on national strategic needs, achieved cross-disciplinary integration, constantly optimized the discipline's layout, and promoted international academic exchanges and collaborations. Using the Frontier Scientific Center on Construction of New Matters and the Cross-disciplinary Scientific Center on New Energy Conversion and Storage as propelling engines, we have built up and supported research platforms and scientific teams specialized in synthetic science, life health, and energy materials. The development of the comprehensive strength of our scientific research and education has witnessed vigorous growth. A great number of our academic leaders and researchers have accomplished many high-level scientific research achievements. In the past three years, more than 2,000 papers have been published in top international academic journals such as Science and Nature Chemistry, and our citation rate for high-level papers ranks as number one in China. More than 300 patents have been granted, and a number of scientific research achievements, such as new green pesticides, chiral drugs, energy batteries, and catalytic materials, are being used to serve the national economy, generating very good economic and social benefits. In 2018, Prof. Zhou Qilin won the "Future Science Award" for physical science.

Without strong support from our country, Nankai Chemistry could never have accomplished this much. Since the founding of New China, Party and state leaders have demonstrated their interest in Nankai University, visiting Nankai Chemistry many times to cordially encourage our faculties and students. On August 13, 1958, and May 28, 1959, the Chairman Mao Zedong and the Premier Zhou Enlai successively visited the chemical plant and research laboratories of our Department of Chemistry. They warmly inspired and motivated people with instructions such as "combine education with production" and "scientific research should serve production." On January 17, 2019, the General Secretary Xi Jinping visited Nankai University. He inspected the College of Chemistry and the State Key Laboratory of Elemento-organic Chemistry, pleasantly interacting with our faculty and student representatives. In his speech, he emphasized that patriotism should be cultivated and deeply integrated into our minds, encouraging us to devote ourselves to the cause of our nation and advised us to become as broadminded as deep oceans and as respectable as high mountains. He urged us to combine our personal goal of 
learning with the grand goal of national rejuvenation to better serve the country; we should strengthen basic research, strive for greater achievement through original and independent innovation, and bravely conquer scientific summits. The General Secretary's entrustment clearly pointed out our responsibilities and stimulated us to take the world's top universities as our standard and strive hard toward the construction of a first-class discipline and fostering development.

To celebrate Nankai University's centennial birthday, we have compiled and published this special issue, reviewing the discipline's developmental process, praising the merits and virtues of the past generations, and expressing the appreciation of the young generation with dedicated and full hearts. We invited young as well as middle-aged academic leaders from Nankai University's College of Chemistry to submit scientific articles and to organize both Chinese and
English special issues. After peer reviews, 13 papers in the Chinese issue and 15 papers in the English issue have been accepted for publication. These papers introduce some of the progress the Nankai University's College of Chemistry has made in chemistry-related research fields. We look forward to strengthening our academic exchanges and collaborations with beloved colleagues at home and abroad to jointly promote the development of chemistry and related interdisciplinary research.

The Science China Chemistry's editor-in-chief Wan Lijun and editor Zheng Jianfen have worked hard to publish these special issues. Herein, we would like to sincerely express our appreciation for their great help. We would also like to take this opportunity to deliver our genuine respect and gratitude to those who have been concerned about, supported, and helped the development of Nankai Chemistry.
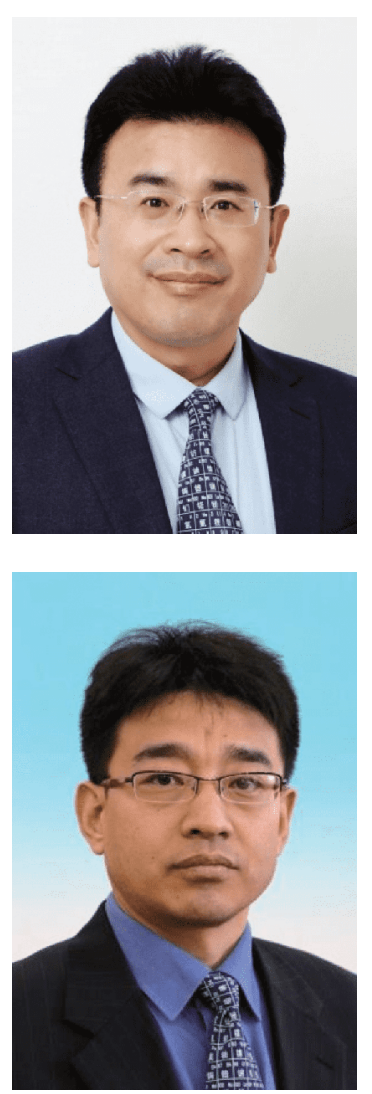

Jun Chen, Professor at Nankai University, Academician of the Chinese Academy of Sciences, and Dean of the College of Chemistry, Nankai University. He received his bachelor's and master's degrees from Nankai University in 1989 and 1992, respectively, and his doctoral degree from Wollongong University, Australia, in 1999. He has been engaged in the chemical research of new energy materials and made important innovative contributions. He has published more than 400 SCI papers in scientific journals such as Nature Chemistry and has been granted 30 invention patents, some of which have been applied to real production. He won second prize in the National Natural Science Award in 2011 and the National "May First" Labor Medal in 2018.

Guangxin Liang, Professor at Nankai University, Vice Dean of the College of Chemistry, Deputy Director of the State Key Laboratory of Elemento-organic Chemistry, Nankai University. He received his bachelor's degree from Nankai University in 1997, his master's degree from the Ohio State University in 2002, and a doctoral degree from the University of California, Berkeley, in 2007. From 2007 to 2009, he was a senior scientist for the Division of Global Pharmaceutical Research and Development, Abbott Laboratories, working in pharmaceutical process research. He joined Nankai University in 2009. His research focuses on the design of user-friendly synthetic strategies and the development of green synthetic tools for the total synthesis of complex natural products with important biological activities. 